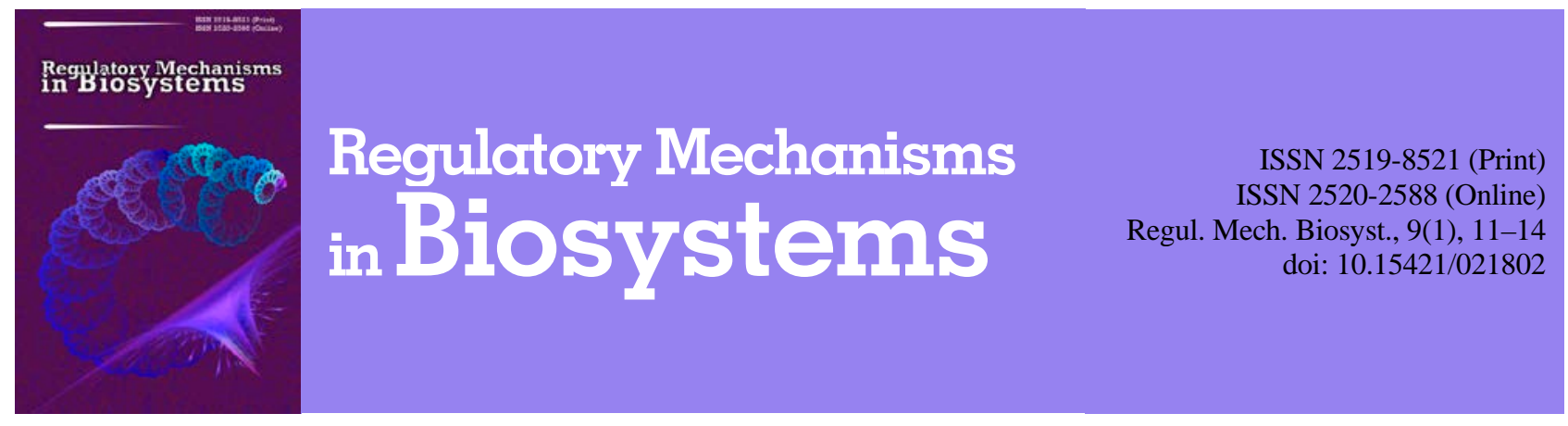

\title{
The role of neuro-specific dihydropyrimidinase-related protein 2 (dpyl2) in spatial memory formation in teleosts
}

\author{
D. V. Garina*, V. V. Bol'shakov*, I. Y. Toropygin**, A. A. Mekhtiev***, A. M. Andreeva* \\ *I. D. Papanin Institute for Biology of Inland Waters, Russian Academy of Sciences, Borok, Russia \\ **V. N. Orekhovich Research Institute of Biomedical Chemistry, Russian Academy of Sciences, Moscow, Russia \\ ***A. I. Karayev Institute of Physiology, National Academy of Sciences of Azerbaijan, Baku, Azerbaijan
}

\section{Article info}

Received 02.01.2018

Received in revised form 28.01.2018 Accepted 30.01.2018

I. D. Papanin Institute for Biology of Inland Waters, Russian Academy of Sciences, 109, Borok, 152742, Russia. Tel.: +7910-824-24-76. E-mail: dvgarina1976@yandex.ru

V. N. Orekhovich Research Institute of Biomedical Chemistry,

Russian Academy of Sciences,

Pogodinskaya st., 10/8,

Moscow, 119121, Russia.

Tel.: +7499-246-69-80.

A. I. Karayev Institute of Physiology, National Academy of Sciences of Azerbaijan, Sharif-Zade st., 2, Baku, AZ1100, Azerbaijan. Tel.: +99-450-336-06-84.

E-mail: arifmekht@yahoo.com
Garina, D. V., Bol'shakov, V. V., Toropygin, I. Y., Mekhtiev, A. A., \& Andreeva, A. M. (2018). The role of neurospecific dihydropyrimidinase-related protein 2 (dpyl2) in spatial memory formation in teleosts. Regulatory Mechanisms in Biosystems, 9(1), 11-14. doi: 10.15421/021802

This article presents the results of an experiment on the influence of serotonin-modulating anticonsolidation protein (SMAP) on the spatial memory formation of juvenile goldfish Carassius auratus (L.) in a maze with food reinforcement. Three experimental fish groups were formed: (1) intact animals, (2) experimental group (fish injected ICV with SMAP in $24 \mathrm{~h}$ before the beginning of training; $2 \mu \mathrm{l}, 1.5 \mathrm{mg} \cdot \mathrm{ml}^{-1}$ ), (3) active control group (fish injected ICV with inactivated SMAP). Goldfishes of the experimental group demonstrated the lowest capability for spatial recognition: the maximum level of performance of the task was on 4th day of the training - 38\%, while the values of this index in fishes of the control and intact groups were $70 \%$ and $63 \%$ respectively. In general, throughout the period of the training the average value of task performance was 16\% in the SMAP-injected fish (in the control and intact groups $-42 \%$ and 53\%, respectively). By using Ds-Na-polyacrylamide gel electrophoresis SMAP compositeon has been revealed. It was found that it consists of 10-12 protein components, among which four proteins dominated. They were identified by mass spectrometry MALDI-TOF: spectrin, dihydropyrimidinase-related protein 2 (DPYL2), tubulin and actin. It has been suggested that the most likely candidate responsible for the negative effects of SMAP on fish memory formation is DPYL2. It was hypothesized that anticonsolidation effect of SMAP is caused by the effect of DPYL2 which blocks the growth of axons or its cytostatic activity which leads to disorders in formation of new neurons in the brain as a result of learning.

Keywords: teleosts; serotonin-modulating anticonsolidation protein; SMAP; learning; spatial memory

\section{Роль нейроспецифичного дигидропиримидиназа подобного белка-2 (dpyl2) в формировании пространственной памяти у костистых рыб}

\author{
Д. В. Гарина*, В. В. Большаков*, И. Ю. Торопыгин**, А. А. Мехтиев***, А. М. Андреева* \\ *Институт биологии внутренних вод имени И. Д. Папанина РАН, Борок, Россия \\ **Научно-исследовательский институт биомедииинской химии имени В. Н. Ореховича РАН, Москва, Россия \\ *** Институт физиологии имени А. И. Караева НАН Азербайджана, Баку, Азербайджан
}

\footnotetext{
Исследовали влияние серотонин-модулируемого антиконсолидационного белка (СМАБ) на формирование пространственной памяти у молоди карася Carassius auratus (L.) в лабиринте с пищевым подкреплением. Опытной группе рыб за 24 ч до начала обучения вводили в область четвертого желудочка мозга 2 мкл СМАБ (1,5 мг/мл), контрольной группе - СМАБ, инактивированный нагреванием, интактная группа не подвергалась инъекции. Караси опытной группы продемонстрировали наихудшую способность к пространственному распознаванию: максимальный уровень обученности отмечался на четвертый день и составил $38 \%$ (в контрольной и интактной группах $70 \%$ и $63 \%$, соответственно), в целом же за все время обучения средний показатель в опытной группе рыб составил 16\% (в контрольной и интактной группах $-42 \%$ и 53\%, соответственно). С помощью SDS-электрофореза в полиакриламидном геле установили состав СМАБ: он представлен девятью белковыми компонентами, среди которых по относительному содержанию доминируют четыре. С помощью массспектрометрии MALDI проведена их идентификация: спектрин, дигидропиримидиназа-подобный белок-2 (DPYL2), тубулин и актин. Поскольку три из четырех указанных белков - структурные, мы предположили, что наиболее вероятный кандидат, ответственный за негативный эффект СМАБ на формирование долговременной памяти у рыб, - это дигидропиримидиназа-подобный белок-2 (DPYL2). Выдвинута гипотеза, что антиконсолидационный эффект СМАБ обусловлен эффектом DPYL2, блокирующим прорастание аксонов или его цитостатической активностью, нарушающей образование в результате обучения новых нейронов в головном мозге.
}

Ключевые слова: рыбы; серотонин-модулируемый антиконсолидационный белок; СМАБ; пространственная память 


\section{Введение}

Память и обучение рыб в раннем онтогенезе, а также приобретенные взрослыми особями навыки лежат в основе успешного существования вида, размножения и освоения им экологической ниши. В настоящее время установлено, что у рыб существует как кратковременная, так и долговременная память (Csányi et al., 1989; Zion et al., 2011), способность к простым (классический условный рефлекс) и довольно сложным формам научения (пространственное распознавание) (Rodriguez et al., 2005). Молекулярные механизмы долговременной памяти рыб в последние десятилетия привлекают все больше внимания исследователей. Получены доказательства участия холинергической и глутаматергической нейротрансмиттерных систем в процессах обучения и памяти у Danio rerio (Cognato et al., 2012). Показана важная роль теленцефалона и его отделов (латерального и медиального паллиума) в формировании эмоциональной, временно́й и пространственной памяти у лучеперых рыб (Broglio et al., 2005, 2010). Дорзолатеральное удаление теленцефалона золотой рыбки приводит к ухудшению пространственного распознавания, сходному с таковым при повреждении гиппокампа млекопитающих (Portavella et al., 2002). Нейрофизиологические исследования свидетельствуют также о вовлечении мозжечка рыб в процессы памяти и обучения, как это наблюдается у высших позвоночных (Rodriguez et al., 2005). Обнаружено, что острый стресс, вызванный феромоном тревоги или кайромоном хищника и примененный непосредственно перед тестированием рыб, значительно ухудшает пространственную и сигнальную память у Danio rerio (Gaikwad et al., 2011). Вместе с тем, в этой области физиологии низших позвоночных существует немало белых пятен.

Серотонин-модулируемый антиконсолидационный белок, или СМАБ, первоначально выявлен в затылочной области коры головного мозга крысы после аппликации серотонина (Mekhtiev, 2000). Название белка обусловлено, с одной стороны, установленной зависимостью его содержания в нервных клетках головного мозга млекопитающих от уровня серотонина (Gasanov \& Mekhtiev, 1991; Mekhtiev et al., 2003), a с другой - негативным влиянием СМАБ на формирование долговременной памяти у животных (Mekhtiev, 2000). Нарушение консолидации следов памяти под действием СМАБ наблюдалось как у высших позвоночных (млекопитающих) в различных условно-рефлекторных моделях обучения (Guseinov \& Mekhtiev, 2012; Mekhtiev et al., 2015), так и у низших (костистых рыб) при введении им СМАБ в желудочек мозга перед обучением (Garina \& Mekhtiev, 2014). Кроме того, описан ряд других эффектов СМАБ, важных для жизнедеятельности организма: участие в обезвреживании токсинов (Movsum-Zadeh et al., 2013), регуляции процессов эмбриогенеза и метаморфоза (Mekhtiev et al., 2016), антиоксидантный (Bakhshalieva et al., 2010), антимутагенный (Mekhtiev et al., 2006) эффекты и некоторые другие.

Участие СМАБ в регуляции столь значимых для нормального функционирования организма процессах привело к мысли о том, что он задействован в одном из ключевых сигнальных каскадов клетки. Целью данной работы являлось 1) исследовать влияние СМАБ на формирование пространственной памяти у рыб; 2) выяснить состав СМАБ с помощью электрофореза в полиакриламидном геле и затем идентифицировать выявленные белковые фракции с помощью масс-спектрометрии MALDI.

\section{Материал и методы исследований}

Схема поведенческого эксперимента. Эксперимент по исследованию влияния серотонин-модулируемого антиконсолидационного белка (СМАБ) на формирование пространственной памяти у рыб проводили на молоди серебряного карася Carassius auratus (L.), выращенной на экспериментальной прудовой базе ИБВВ РАН (п. Борок) и затем содержавшейся в аквариальных условиях в течение 4 месяцев. Возраст молоди на момент начала опыта составил 6-7 месяцев, средняя масса - 7,8-9,7 г, средняя длина 8,5-9,0 см. За 7 суток до начала эксперимента рыб взвеши- вали, измеряли и помещали в индивидуальные контейнеры объемом 4 л с принудительной аэрацией. Процедуру внутричерепной инъекции препаратов проводили под наркозом по ранее апробированной методике (Garina \& Mekhtiev, 2014). Опытной группе рыб $(\mathrm{n}=8)$ вводили в область четвертого желудочка мозга 2 мкл нативного СМАБ (1.5 мг/мл), контрольной группе (n = 10) СМАБ в той же дозе, инактивированный нагреванием на водяной бане в течение 40 мин при температуре $55^{\circ} \mathrm{C}$. Интактную группу карасей $(n=8)$ не подвергали каким-либо инъекциям. Через 24 ч после инъекции регистрировали динамику формирования навыка нахождение корма, находящегося в определенном месте лабиринта (рис. 1), в течение 10 сеансов обучения.

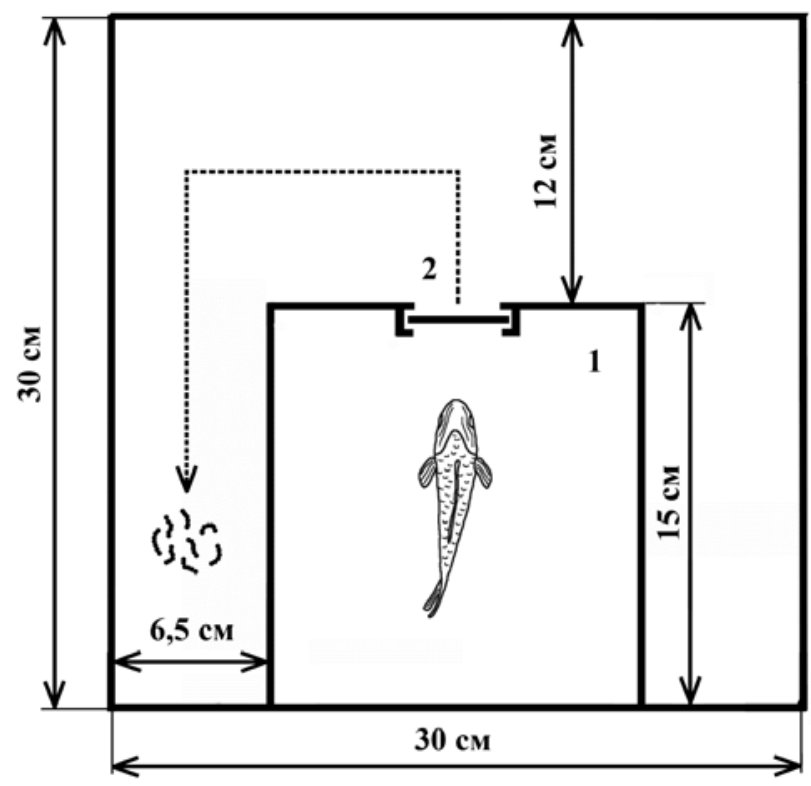

Рис. 1. Схема экспериментальной установки для исследования пространственной памяти у рыб: 1 - стартовая камера; 2 - заслонка, закрывающая выход из стартовой камеры

В течение суток обучение проводили однократно (один сеанс). Регистрировали факт выполнения или невыполнения задания (нахождение и поедание корма) особью в течение 10 мин после открытия заслонки в стартовой камере.

Статистическую обработку полученных результатов проводили с помощью однофакторного дисперсионного анализа ANOVA (Statistica 7.0, StatSoft Inc., USA) при уровне значимости P <0,05.

Препарат. Серотонин-модулируемый антиконсолидационный белок (СМАБ) получен в Институте физиологии имени А. И. Караева НАН Азербайджана; выделен из мозга быка с использованием методов высаливания сульфатом аммония и колоночной гель-хроматографии на сефадексе G-150, под контролем твердофазного иммуноферментного анализа. Препарат доводили физиологическим раствором для холоднокровных животных $(\mathrm{pH} 7,3)$ до концентрации 1,5 мг/мл и хранили до начала работы при температуре $-80^{\circ} \mathrm{C}$.

Исследование состава СМАБ и идентификация белков. Исследование состава СМАБ проводили в $12,5 \%$ Ds-Na-ПААГ в восстанавливающих условиях (Laemmli, 1970). В качестве маркеров молекулярной массы использовали набор белков PageRulerTM Prestained Protein Ladder Plus (10, 15, 27, 35, 55, 70, 100, 130, 250 кДа) (Fermentas). Расчет величин молекулярных масс белков (MW) осуществляли с помощью программы ONE-Dscan, Ver 1.31 (Scananalytic Inc.). После электрофореза из геля вырезали участки, содержавшие мажорные фракции белков, подвергали их трипсинолизу и затем идентифицировали белки с помощью масс-спектрометрии MALDI. Масc-спектры регистрировали на времяпролетном масс-спектрометре BRUKER Ultraflex II (“Bruker Daltonics”, Германия). Идентификацию белков проводили в системе Mascot (опция «пептидный фингерпринт», www.matrixscience.com). Поиск 
проводили в базе данных NCBI.nr среди белков всех организмов. Кандидатов, имеющих параметр достоверности score $>92$ (P < 0,05), считали достоверно определенными.

\section{Результаты}

Влияние ICV-инъекции СМАБ на пространственное распознавание в лабиринте у карасей. Караси интактной группы обучались достаточно быстро: уже в первом сеансе обучения корм находили 3 особи из 8 (38\%) (рис. 2).

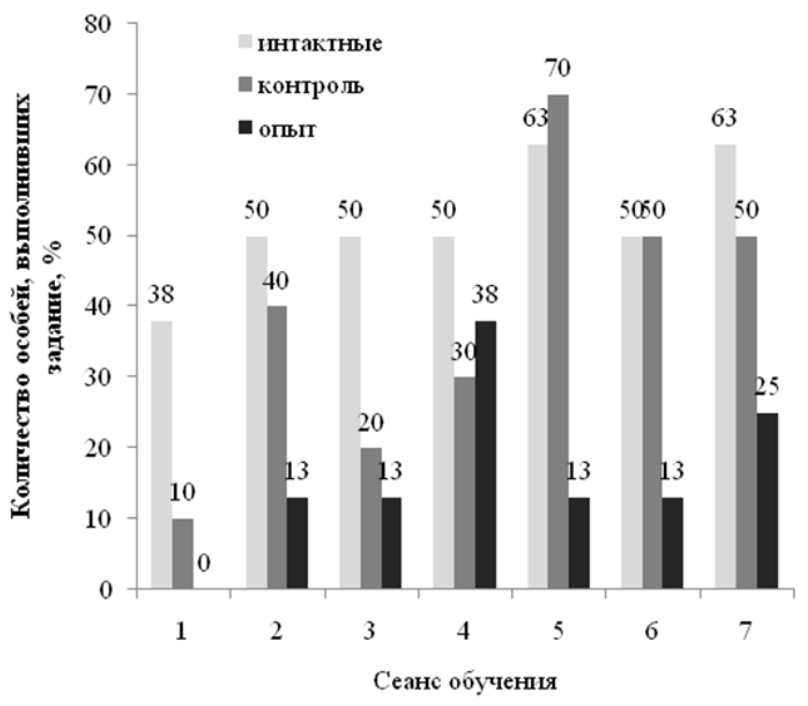

Рис. 2. Динамика формирования навыка у карасей находить корм в лабиринте

Уровень обученности рыб постепенно увеличивался и достигал максимума на пятые сутки (63\%). Рыбы из группы активного контроля обучались в целом хуже, однако на пятые сутки у них выполняли задание $70 \%$ особей. У карасей опытной группы максимальный уровень обученности наблюдался на четвертый день и составил $38 \%$, в целом же за все время обучения средний показатель составил $16 \%$ (в контрольной и интактной группах -42 и $53 \%$ соответственно) $(\mathrm{P}<0,05)$.

\section{Таблища 1}

Идентификация белков в составе СМАБ

\begin{tabular}{|c|c|c|c|c|c|}
\hline $\begin{array}{l}\text { Номер фракции белка } \\
\text { на электрофореграмме }\end{array}$ & Кандидатный белок (NCBI) & $\begin{array}{c}\text { Accession number } \\
\text { (NCBI) }\end{array}$ & MW, Da calc $/ \mathrm{obs}^{2}$ & Score $^{3}$ & Coverage, ${ }^{4} \%$ \\
\hline 1 & Spectrin beta chain, non-erythrocytic 1 isoform X2 [Bos taurus] & gi|528968379 & $272512 / 241840$ & 126 & 14 \\
\hline 2 & Dihydropyrimidinase-related protein 2 [Bos taurus] & gi|115496400 & $62239 / 56540$ & 188 & 45 \\
\hline 3 & Tubulin beta-4A chain isoform X10 [Orcinus orca] & gi|821404056 & $40540 / 52110$ & 158 & 53 \\
\hline 4 & Actin, cytoplasmic 2 [Canis lupus familiaris] & gi|924442847 & $41711 / 39570$ & 109 & 40 \\
\hline 5 & Actin, cytoplasmic 2 [Macaca fascicularis] & gi|54896078 & $41722 / 32260$ & 119 & 37 \\
\hline
\end{tabular}

Примечание: ${ }^{1}$ - расчетная величина молекулярной массы; ${ }^{2}$ - экспериментальная величина молекулярной массы; ${ }^{3}$ - величина достоверности; ${ }^{4}$ - перекрывание аминокислотных последовательностей.

\section{Обсуждение}

Таким образом, нами впервые получены свидетельства негативного влияния серотонин-модулируемого антиконсолидационного белка на формирование пространственной памяти у костистых рыб. Анализ состава СМАБ показал, что он состоит из нескольких белковых компонентов, при этом по относительному содержанию преобладают четыре белка. Параметр достоверности (score) для всех белков выше 92 (109-188); величины перекрывания аминокислотных последовательностей (coverage) четырех белков и их гомологов удовлетворительны (14-53); величины расчетных и экспериментальных молекулярных масс белков (MW) близки. Кроме того, экспериментальный и кандидатные виды животных, у которых обнаружены белки со сходной структурой, принадлежат одному классу Mammalia. В целом указанные факты позволяют утверждать надежность проведенной идентификации белков.
Электрофоретический анализ состава СМАБ. Исследование состава СМАБ с помощью электрофореза в денатурирующих условиях показало, что он представлен девятью компонентами, среди которых по относительному содержанию доминировали четыре (рис. 3, фракции 1-4). Все четыре фракции отобраны для масс-спектрометрического анализа.

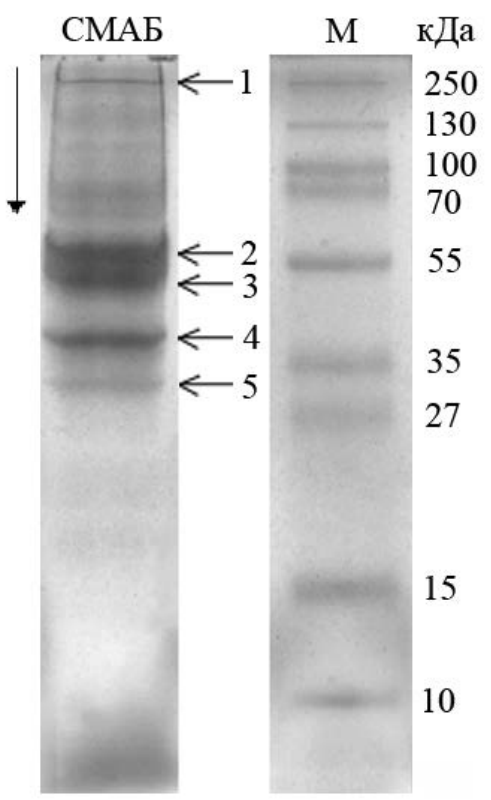

Рис. 3. SDS-электрофорез СМАБ: слева (столбик «СМАБ»): электрофореграмма СМАБ; стрелки справа указывают на локализацию фракций СМАБ (1-5), взятых на последующий анализ MALDI-TOF; стрелка слева - направление электрофореза; справа (столбик «М»): локализация маркеров молекулярной массы PageRulerTM Prestained Protein Ladder Plus (Fermentas) на электрофореграмме; цифрами обозначены молекулярные массы стандартных белков-маркеров (кДа)

Масс-спектрометрический анализ белков в составе СМАБ. Среди идентифицированных в составе СМАБ четырех белков оказались спектрин (1), дигидропиримидиназа подобный белок-2 (2), тубулин (3) и актин (4) (табл. 1). 
сонов и клеточной миграции (Schmidt \& Strittmatter, 2007; Nakamura et al., 2000). Присутствие в составе СМАБ тубулина и актина, повидимому, обусловлено их взаимодействием с CRMP2 в клетке. Поскольку фракционирование СМАБ происходит в неденатурирующих (в отсутствии детергентов) условиях, дигидропиримидиназа подобный белок-2 элюируется с гель-хроматографической колонки G-150 в комплексе с тубулином и актином, одним пиком.

Поскольку в основе обучения животных лежит образование новых связей между нейронами, а внутримозговое введение СМАБ млекопитающим и рыбам перед выработкой у них условных рефлексов приводило к нарушению формирования у них памяти (Guseinov \& Mekhtiev, 2012; Garina \& Mekhtiev, 2014; Mekhtiev et al., 2015), можно предположить, что негативный эффект СМАБ на формирование пространственной памяти у рыб в настоящей работе обусловлен эффектом DPYL2, блокирующим прорастание аксонов, вовлеченных в формирование памяти нейронов. Кроме того, поскольку показано, что в результате обучения происходит образование новых нейронов в ряде структур головного мозга животных (Sherstnev et al., 2010, 2016; Deng et al., 2010; Yau et al., 2015), то антиконсолидационные эффекты СМАБ также могут быть связаны с цитостатической активностью DPYL2.

\section{Заключение}

В настоящем исследовании впервые установлено, что серотонин-модулируемый антиконсолидационный белок (СМАБ) оказывает выраженное негативное влияние на формирование пространственной памяти у костистых рыб. В состав препарата СМАБ входят девять белковых компонентов, среди которых доминируют четыре: спектрин, дигидропиримидиназа подобный белок-2, тубулин и актин. Полученные результаты позволяют предположить, что антиконсолидационный эффект СМАБ обусловлен эффектом DPYL2, блокирующим прорастание аксонов, или его цитостатической активностью, нарушающей образование в результате обучения новых нейронов в головном мозге рыб. Для подтверждения этой гипотезы необходимы дополнительные исследования с очищенным препаратом DPYL2.

Благодарности

Авторы выражают благодарность И. П. Рябцевой за техническую помощь при проведении работы.

\section{References}

Bakhshalieva, R. R., Mekhtiev, A. A., \& Kasimov, R. Y. (2010). Participation of serotonin-modulated anticonsolidation protein in mediation of action of adverse factors on lipid peroxidation level in tissues of sturgeon fry Acipenser güldenstädti persicus. Journal of Evolutionary Biochemistry and Physiology, 46(5), 442-446.

Broglio, C., Gómez, A., Durán, E., Ocaña, F. M., Jiménez-Moya, F., Rodríguez, F., \& Salas, C. (2005). Hallmarks of a common forebrain vertebrate plan: Specialized pallial areas for spatial, temporal and emotional memory in actinopterygian fish. Brain Research Bulletin, 66(4-6), 277-281.

Broglio, C., Rodríguez, F., Gómez, A., Arias, J. L., \& Salas, C. (2010). Selective involvement of the goldfish lateral pallium in spatial memory. Behavioural Brain Research, 210(2), 191-201.

Cognato, G. P., Bortolotto, J. W., Blazina, A. R., Christoff, R. R., Lara, D. R., Vianna, M. R., \& Bonan, C. D. (2012). Y-maze memory task in zebrafish (Danio rerio): The role of glutamatergic and cholinergic systems on the acquisition and consolidation periods. Neurobiology of Learning and Memory, 98(4), 321-328.

Csányi, V., Csizmadia, G., \& Miklosi, A. (1989). Long-term memory and recognition of another species in the paradise fish. Animal Behavior, 37(6), 908-911.

Deng, W., Aimone, J. B., \& Gage, F. B. (2010). New neurons and new memories: How does adult hippocampal neurogenesis affect learning and memory? Nature Reviews Neuroscience, 11(5), 339-350.
Gaikwad, S., Stewart, A., Hart, P., Wong, K., Piet, V., Cachat, J., \& Kalueff, A. V. (2011). Acute stress disrupts performance of zebrafish in the cued and spatial memory tests: The utility of fish models to study stress-memory interplay. Behavioral Processes, 87(2), 224-230.

Garina, D. V., \& Mekhtiev, A. A. (2014). Effect of serotonin-modulated anticonsolidation protein on formation of long-term memory in the learning model of active avoidance in the carp (Cyprinus carpio). Journal of Evolutionary Biochemistry and Physiology, 50(1), 49-56.

Gasanov, G. G., \& Mekhtiev, A. A. (1991). Detection of serotonin-modulating protein fraction and study of its participation in organization of the passive avoiding behavior. Bulletin of Experimental Biology and Medicine, 112(7), 5-7.

Guseinov, S. B., \& Mekhtiev, A. A. (2013). Studies of the role of serotoninmodulating anticonsolidation protein in memory formation in rats in a shuttle box. Neuroscience and Behavioral Physiology, 43(5), 551-556.

Laemmli, U. K. (1970). Cleavage of structural proteins during the assembly of the head of bacteriophag. Nature, 227(4), 680-685.

Mekhtiev, A. A. (2000). Detection of protein with anticonsolidation properties in the rat brain. Bulletin of Experimental Biology and Medicine, 130(8), 739-742.

Mekhtiev, A. A., Gaisina, A. A., Palatnikov, G. M., \& Kasimov, R. Y. (2006). Decrease in activity of the serotoninergic system during mutagenesis. Bulletin of Experimental Biology and Medicine, 142(6), 611-613.

Mekhtiev, A. A., Gaisina, A. A., Voronezhskaya, E. E., Khabarova, M. Y., Gudratov, N. O., \& Huseynov, S. B. (2016). Uchastie serotonin-moduliruemogo anticonsolidatsionnogo belka $\mathrm{v}$ regulyatsii razvitiya embrionov bol'shogo prudovika (Lymnaea stagnalis) i sarcomy l'yuisa u myshej gibridnoji liniji (FL C57B2/6 X DBA) [Engagement of serotonin-modulating anticonsolidation protein in regulation of embryogenesis of Lymnaea stagnalis and Lewis sarcoma in hybrid mice (FL C57B2/6 X DBA)]. Rossijskij Fiziologicheskij Zhumal imeni I. M. Sechenova, 102(4), 490-499 (in Russian).

Mekhtiev, A. A., Kozyrev, S. A., Nikitin, V. P., \& Sherstnev, V. V. (2003). Izbiratel'noe vliianie antitel $\mathrm{k}$ belku SMP-69 na aktivnost' komandnykh nejronov oboronitel'nogo povedenija vinogradnykh ulitok [Selective effect of the antibody to protein SMP-69 on activity of the defence behavior command neurons in grape snail]. Rossijskij Fiziologicheskij Zhurnal imeni I. M. Sechenova, 89, 389-396 (in Russian).

Mekhtiev, A. A., Panahova, E. N., Rashidova, A. F., \& Guseinov, S. B. (2015). Engagement of serotonin-modulating anticonsolidation protein in memory formation and suppression of drug addiction and epileptic seizures. In: $\mathrm{Li}$, M. D. (Ed.). New developments in serotonin research. Nova Science Publishers, New York. pp. 123-143.

Movsum-Zadeh, S. K., Mekhtiev, A. A., Mekhtiev, K. S., Telford, W. G., Gaisina, A. A., \& Zey'nalov, S. K. (2013). Detoxikatsionnye svojstva serotonin-moduliruemogo anticonsolidatsionnogo belka $\mathrm{v}$ otnoshenii toxinov khimicheskoj i bacterial'noj prirody [Detoxic properties of serotonin-modulating anticonsolidation protein to toxins of chemical and bacterial origin]. Izvestiya NAN Azerbajdzhana. Seriya Biologicheskie i Meditsinskie Nauki, 68(1), 24-29 (in Russian).

Nakamura, F., Kalb, R. G., \& Strittmatter, S. M. (2000). Molecular basis of semaphorine-mediated axon guidance. Journal of Neurobiology, 44(2), 219-229.

Portavella, M., Vargas, J. P., Torres, B., \& Salas, C. (2002). The effects of telencephalic pallial lesions on spatial, temporal, and emotional learning in goldfish. Brain Research Bulletin, 57(3-4), 397-399.

Rodriguez, F., Durán, E., Gómez, A., Ocaña, F. M., Ávarez, E., Jiménez-Moya, F., Broglio, C., \& Salas, C. (2005). Cognitive and emotional functions of the teleost fish cerebellum. Brain Research Bulletin, 66(4-6), 365-370.

Schmidt, E. F., \& Strittmatter, T. M. (2007). The CRMP family of proteins and their role in Sema3A signaling. Advances in Experimental Medicine and Biology, 600, 1-11.

Sherstnev, V. V., Gruden', M. A., Golubeva, O. N., Solov'eva, O. A., \& Aleksandrov, Y. I. (2015). Long-lived newly formed neurons in the mature brain are involved in the support of learning and memory processes. Journal of Neurochemistry, 9(1), 13-19.

Sherstnev, V. V., Yurasov, V. V., Storozheva, Z. I., Gruden', M. A., \& Proshin, A. T. (2010). Neurogenesis and apoptosis in the mature brain during formation and consolidation of long-term memory. Joumal of Neurochemistry, 4(2), 109-115.

Yau, S., Li, A., \& So, K.-F. (2015). Involvement of adult hippocampal neurogenesis in learning and forgetting. Neural Plasticity, Article ID 717958.

Zion, B., Karplus, I., Grinshpon, J., Rosenfeld, L., \& Barki, A. (2011). Periodic reinforcement of acoustically conditioned behavior in St. Peter's fish, Sarotherodon galilaeus, for ranching purposes. Aquaculture, 315(3-4), 394-399. 